\title{
Dropout in Rural Higher Education: A Systematic Review
}

\author{
Alfredo Guzmán ${ }^{1,2 *}$, Sandra Barragán ${ }^{2}$ and Favio Cala Vitery ${ }^{2}$ \\ ${ }^{1}$ School of Economic and Administrative Sciences, Corporación Universitaria de Asturias, Bogotá, Colombia, ${ }^{2}$ Faculty of Natural \\ Sciences and Engineering, Universidad de Bogotá Jorge Tadeo Lozano, Bogotá, Colombia
}

\section{OPEN ACCESS}

Edited by:

Ana B. Bernardo,

University of Oviedo, Spain

Reviewed by:

Alexandra M. Araújo,

Portucalense University, Portugal

David Orellana,

Corporación Universitaria

Iberoamericana, Colombia

Fabiola Sáez-Delgado,

Universidad Católica de la Santísima

Concepción, Chile

*Correspondence:

Alfredo Guzmán Rincón

alfredo.guzman@asturias.edu.co

Specialty section:

This article was submitted to Higher Education,

a section of the journal

Frontiers in Education

Received: 19 June 2021

Accepted: 27 August 2021

Published: 08 September 2021

Citation:

Guzmán A, Barragán S and Cala Vitery F (2021) Dropout in Rural Higher Education: A

Systematic Review.

Front. Educ. 6:727833.

doi: 10.3389/feduc.2021.727833
Student dropout in higher education has been of great interest to the academic community, state and social actors over the last three decades, due to the various effects that this event has on the student, the family, higher education institutions, and the state itself. It is recognised that dropout at this level of education is extremely complex due to its multi-causality which is expressed in the existing relationship in its explanatory variables associated with the students, their socioeconomic and academic conditions, as well as the characteristics of the educational institutions. Thus, the aim of this article was to identify the individual, socioeconomic, academic, and institutional explanatory variables involved in student dropout in rural populations, based on a synthesis of the evidence available in the SCOPUS database. In order to achieve it, a mixed systematic review was defined under the PRISMA 2020 method. The analysis was approached in two stages; the first concerned the identification of the documents and the conformation of the sample, where 21 documents were distinguished for effectively dealing with dropout in rural higher education; and the second corresponded to the procedures defined for the development of the bibliometric analysis and synthesis of the information found in the documents. The results showed the distribution of studies by country, years of publication, the categorisation of the documents in SCOPUS, their classification by type and the methodologies used in the development of the studies analysed, as well as the variables that have been addressed in previous research. In this way, it is concluded that the results of the studies are not generalisable, either because of the size of the sample or because of the marked social asymmetries that exist in some countries, which can make the findings lack significance; on the other hand, the interest in research on variables associated with individual and academic determinants to explain rural student dropout is highlighted. In addition, some future research lines which can be addressed as a complement to the current view of the dropout event in rural higher education were identified.

Keywords: dropout, higher education, rural students, systematic review, scopus, bibliometric analysis

\section{INTRODUCTION}

In the last three decades, the study of student dropout in higher education has become one of the lines of research of greatest interest for the academic community, state and social actors due to the high rates of this event, its multi-causality and the effects or consequences it has for the individual, the family, Higher Education Institutions (HEIs), society in general and the state. Considering what has been stated, it is also recognised that dropout rates worldwide have not been controlled and, on the contrary, have increased from an aggregate perspective, being sharpened by the health, economic and 
social crisis derived from COVID-19, which indicates the ineffectiveness of the actions of governments and HEIs, represented in public policies, the establishment of retention and graduation plans (P\&GO for its Spanish acronym) and early warning systems (SAT for its Spanish acronym) (Marquez-Vera et al., 2013; Orellana et al., 2021; UNESCO, 2021). An example of this is the situation in OECD countries where the dropout rate rose from 35\% in 2005 to $64.5 \%$ in 2018 , and in countries such as Luxembourg, Hungary, Sweden, Czech Republic and Slovakia this rate was higher than 70\% (OECD, 2018); or the particular case of Latin America, which has historically had high levels of dropout in higher education, close to $54 \%$, and which are expected to increase as an effect of COVID-19 due to the strong social asymmetries that exist in the region (Becerra et al., 2020; UNESCO, 2021).

Faced with the multi-causality of dropout, efforts have been made to establish the variables that explain current dropout rates and the causes that lead students not to complete their higher education studies, which has resulted in various perspectives and the development of tools that allow decision-makers to have a holistic view of dropout prevention and mitigation (Kehm et al., 2019). That said, research has focused on analysing the influence of specific variables on the materialisation of dropout based on individual student conditions such as age, gender, marital status, family environment, intrinsic motivations and academic selfregulation (e.g., Ghignoni, 2017; Arias-Velandia et al., 2018; Behr et al., 2020); the student's socioeconomic background exemplified by the socioeconomic stratum of the dwelling he or she lives in, family income, economic dependency and the macro-economic environment of the country (e.g., Contreras, 2017; Behr et al., 2020; Palacio et al., 2020; Schmitt et al., 2020); the academic factors represented in the development of competencies prior to entry into higher education, secondary school graduation tests, levels of satisfaction in the training programme and the number of courses concurrently taken (e.g., Guzmán, et al., 2020a; Heidrich, 2018); and finally, institutional circumstances in relation to HEI policies, the technological and pedagogical resources provided by the educational institution, the level of interaction with teachers and students and the pedagogical model (e.g., Armstrong et al., 2018; Choi and Kim, 2018).

On the other hand, the analysis of the multi-causality of dropout has been widely linked to the construction of qualitative, quantitative and mixed models, with the aim of explaining the event in terms of multiple variables; of such studies, the developments made by Spady (1970), Tinto and Cullen (1973), Fishbein and Ajzen (1975), as well as Tinto (1975; 1987), which formed the basis of subsequent studies, and, more recently, Barragán and González (2017), Pérez et al. (2019), Venegas-Muggli (2020), Kilian et al. (2020), SegoviaGarcia and Said-Hung (2021), among others.

However, the consequences of dropout for the actors in the tertiary education subsystem are usually varied. Thus, in the case of students, dropout represents the affectation of learning factors related to emotion, cognition, motivation, among others (Hällsten, 2017), which has long-term repercussions on various difficulties, especially in terms of their work performance (Hällsten, 2017; Sosu and Pheunpha, 2019). For the family, the student's dropout symbolises a sunk cost, due to the expenses were incurred to cover the studies which will never be recovered, (Moreno et al., 2019), as well as the destruction or impossibility of building long-term social capital that allows changing the family's future conditions in both educational and socioeconomic aspects (Ghignoni, 2017). As far as HEIs are concerned, the materialisation of this event means a difficulty in fulfilling their substantive functions (Voelkle and Sander, 2008) by affecting the quality conditions of the training programmes and the reputation of the institutions (Ortiz and Dehon, 2013), as well as impacting the income of HEIs in terms of student enrolments, since dropout represents an opportunity cost that translates into the loss of financial support (Barragán and Rodríguez, 2015).

Finally, in the case of the state, the consequences of dropping out can be categorised as financial and social. In this sense, the materialisation of student dropout represents a damage to the resources made available by the State, since " (...) students who do not graduate on time (or at all) when they receive public funding consume valuable fiscal resources, which in many cases are not recoverable" (The World Bank, 2017, p. 14); and, on the other hand, dropout prevents the consolidation of the benefits of higher education by making it impossible to improve the average income of the population (Cristia and Pulido, 2020), increase the productivity of the economy (Cristia and Pulido, 2020), consolidate democratic processes (Lance, 2011) and reduce crime (Chalfin and Deza, 2019). In brief, student dropout in higher education can slow down the development and social transformation sought by implementing public policies related to access to higher education, hence the importance of its prevention and mitigation (Guzmán et al., 2021).

Under the widespread interest of the academic community, state, and social actors in the study of dropout at the higher education level, multiple opportunities have been identified for understanding the event, especially in student groups such as those from or located in rural areas, ethnic minorities and those displaced by armed conflict, which have not been widely studied. This has been evidenced in literature reviews focused on identifying the variables that influence dropout by educational modality, (e.g., Kara et al., 2019; Guzmán et al., 2020b; Orellana et al., 2021), the role of the intrinsic and extrinsic context to the student (Broadbent and Poon, 2015), the methodological approach to the study of dropout (Rodriguez Urrego, 2019) and the organisational perspective of the effects of dropout (Fonseca and Garcia, 2016). Based on what has been previously stated, a holistic view of this event in rural higher education is required, due to the efforts made in recent years by states and HEIs to link a population that was marginalised, especially in developing countries, to the educational subsystem and to materialise the direct and indirect benefits of a higher level of education for the population, which are mitigated by the high dropout rates in rural areas. In addition, the lack of such a holistic view makes it difficult for decision-makers to develop effective and efficient public and institutional policies by governments and HEIs to deal with the event of dropout. Thus, the aim of this article was to identify the individual, 
socioeconomic, academic, and institutional explanatory variables involved in student dropout in rural populations, based on a synthesis of the evidence available in the SCOPUS database. Hence, student dropout in rural higher education merits a comprehensive view of the explanatory variables which affect it, in order to move towards its prevention and mitigation by the various actors in the tertiary education subsystem, especially the State and HEIs (Gibbs, 1998; Byun et al., 2012; Guzmán et al., 2021; Snyder and Dillow, 2021). To guide the systematised review presented here, the following research questions were proposed:

RQ1: What trends have been followed in the study of student dropout in rural higher education in terms of the characteristics of publications and methodologies?

RQ2: What progress has been made in the study of student dropout in rural higher education, based on the determinants of study (individual, socio-economic, academic, and institutional)?

Accordingly, this article is structured in four main sections. The first section describes the conceptualisation of dropout and the theoretical reference model; the second, the methodology used to achieve the objective; the third, the main findings obtained with the implementation of the methodology; and the fourth, the discussions, conclusions, and final considerations.

\section{DROPOUT AND THE THEORETICAL REFERENCE MODEL}

When referring to student dropout, multiple meanings have been developed both by the academic community and by state and social agents, which generates diverse points of view and an enrichment of the discussion around it (Kehm et al., 2019), in other words, these perceptions are not mutually exclusive. As Guzmán et al. (2021) expressed it, the multiplicity of definitions derives from specific purposes of analysis, and they have the capacity to complement each other in order to give a broader view of dropping out. In relation with the wide variety of conceptual and operational definitions of this event, this article is based on the one given by the Alpha Guidance Project. Thus, drop-out is defined as "the cessation of the relationship between the student and the training programme leading to a higher education degree before the degree is achieved. An event of a complex, multidimensional and systemic nature, which can be understood as cause or effect, failure or reorientation of a training process, choice or obligatory response, or as an indicator of the quality of the education system" (ALFA GUIA Project DCI-ALA/2010/94, 2013, p. 6).

This definition encompasses both the analysis of specific variables and of the models developed. Consequently, its use allows the theoretical framework of student dropout to be understood from a holistic viewpoint, integrating the perspectives of the academic community, state and social agents. With this integration of perspectives, the study of dropout has been carried out from a multidisciplinary orientation in which the sociological, interactionist, organisational, psychological and economic approach are highlighted (Lázaro Alvarez et al., 2020), and have resulted in the analysis of variables intrinsic and extrinsic to the student, categorising them into four determinants: individual, socioeconomic, academic and institutional (Fonseca and García, 2016; Barragán and González, 2017; Donoso and Schiefelbein, 2021; Guzmán et al., 2021).

Thus, the sociological approach sets the basis for the study of dropout in higher education, assessing the influence of external factors on the student. The contributions made by Spady (1970) explained the event in terms of Durkheim's theory of suicide, in which it is argued that this action is the result of the subject's disconnection from the social system, and therefore, dropout is explained as the lack of social integration of the student into the higher education environment. In addition, this approach considered variables other than social integration in the HEI such as family, expectations and demands that affect the student's academic potential and performance.

Subsequently, the mainstream study of drop-out emerged with its basis on the interactionist and organisational approaches in which this event is explained by the student's academic and social interaction in the HEI. An example of this approach was the model developed by Tinto $(1975 ; 1987)$ in which the student's emotional and intellectual background was taken as a point of reference, also involving various individual, academic, and family characteristics that directly affect the student's permanence in the HEI. Later mainstream models, such as Bean (1986) or Heublein et al. (2010), incorporated other related variables such as funding opportunities for tuition and other costs associated with the level of education, organisational characteristics of the HEI and student effort, thus providing a broader picture of the dropout event.

From the psychological perspective, the student's own characteristics and attributes were incorporated, considering aspirations, values, personality, motivation, and expectations of success, so that the individual and his or her variables associated with dropout were observed (Ethington, 1990). This approach has grouped studies that include psychological aspects of the student from the perspective of the educational sciences. Prior to the research carried out by Ethington (1990), the explanatory variables of dropout associated with the student's psyche were not incorporated into the models, which is why the variables categorised in the individual determinant have been incorporated from his analysis. Recent studies have shown the influence of variables such as self-determination (Jeno et al., 2018), personality (Alkan, 2014), introversion (Migali and Zucchelli, 2017) and neuroticism (Migali and Zucchelli, 2017).

Finally, the economic approach has privileged the socioeconomic context of the student and his or her family by evaluating the cost-benefit ratio of staying or dropping out of higher education (Palacio et al., 2020), the influence of family income on the probability of not completing the educational process (Adrogué and García de Fanelli, 2018), social class as a constraint to the creation of social capital (Palacio et al., 2020), among others. While most studies have focused on the student and the family, they have also assessed the impact of the drop-out event on the operational income of HEIs and their financial sustainability (Barragán and Rodríguez, 2015).

Based on this interdisciplinary orientation of the study of dropout and the categorisation of the explanatory variables into 


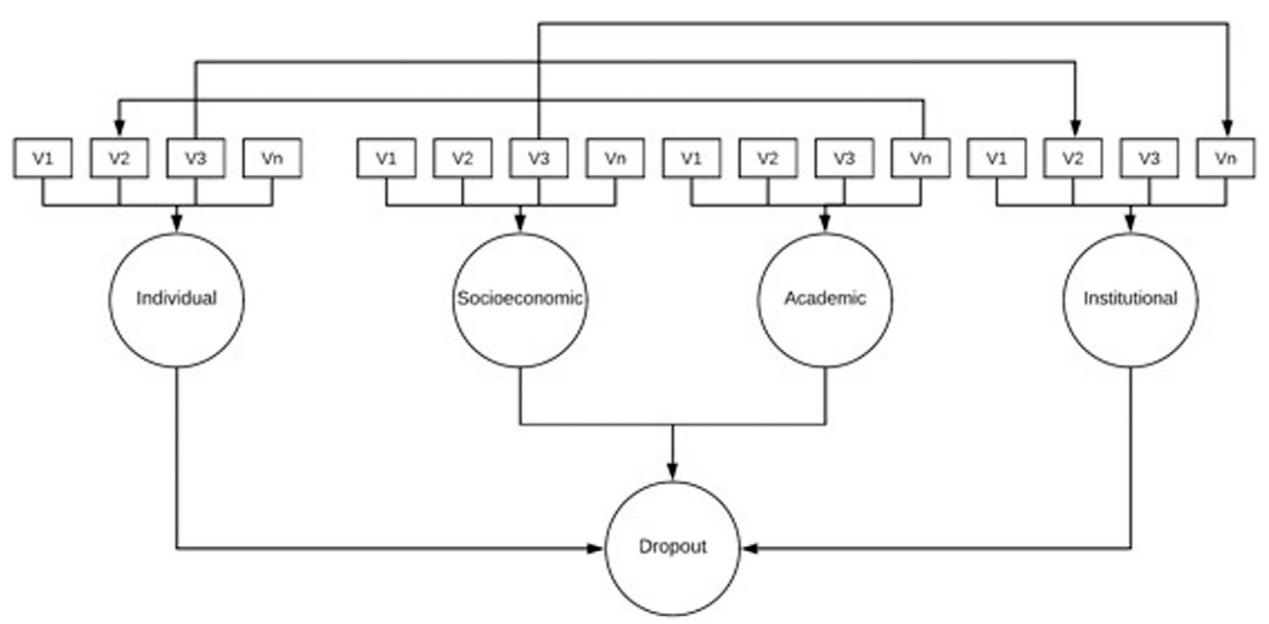

FIGURE 1 | Conceptual model of determinants of dropout. Note: Each determinant groups $n$ variables v1, v2,...,vn as exemplified in the individual determinant. A variable can have an impact on other variables in the same or a different determinant.

the four determinants, this article is linked to the conceptual model described in Figure 1, which has been widely used in previous research (e.g., Barragán and González, 2017; Klein, 2019; Radovan, 2019; Kemper et al., 2020; Vera et al., 2020; Guzmán et al., 2021) as well as in the development of public policies such as in the Colombian case (Ministry of National Education, 2009), because it is adaptive to the educational modality or type of student population, the new realities of the higher education context, as well as allowing the development of explanatory and predictive models of dropout in higher education (Guzmán et al., 2021).

Thus, the determinants are conceptualised as follows:

- Individual: describes the characteristics associated with the student and his/her personal environment that have a direct influence on the decision to leave the study process unfinished. Examples of the variables related to this determinant are age, gender, marital status, position in the number of siblings, health problems at the time of enrolment at HEI, family environment, fulfilled expectations, family and personal obligations, motivation in relation to the teaching and learning process, selfregulation, and time management.

- Socioeconomic: this refers to the influence of the social and economic context in which the student is immersed, and which may lead him/her not to complete the higher education process. Among the variables related to this determinant are the stratum, the employment situation, the economic income of the family nucleus and of the student, the economic dependence, and the macroeconomic environment of the country.

- Academic: these are all those variables related to the teaching and learning process both in previous levels of education and in higher education that may lead students to drop out. Among the variables of this determinant, the following stand out: previous academic performance, courses taken before higher education, secondary school graduation tests, results of admission exams to higher education, teaching qualifications and levels of satisfaction with the academic programme.

- Institutional: refers to all the characteristics of the HEIs that allow for the correct development of the learning process and others associated with the student, which, if they generate dissatisfaction in the student, may lead him/her not to complete the learning process. Examples of explanatory variables associated with the determinant are institutional policies, funding services, pedagogical resources, the level of interaction between teachers and students, as well as academic support.

\section{METHODOLOGY}

To carry out the systematic review developed in this article, and in order to achieve the proposed objective, a mixed study was defined under the PRISMA 2020 method. This method was intended for use in reviews that include syntheses of quantitative and qualitative information (Page et al., 2021). Thus, under this approach, two stages were carried out. The first related to the identification of the documents (records); and the second to the analysis and synthesis of the findings.

\section{Stage One: Identification of the Documents and Sample Formation}

In order to identify the literature with the greatest impact on higher education dropout in the rural student population, documents were searched in SCOPUS, which is a curated database of abstracts and citations of scientific documents (e.g., articles, books and conference proceedings), whose content is generally considered of the highest quality by the academic community, since each of the grouped documents is 
TABLE 1 | Ratio of records found by search equation.

TITLE-ABS-KEY (Rural AND bachelor AND drop-out)

TITLE-ABS-KEY (Rural AND bachelor AND "persistence")

TITLE-ABS-KEY (Rural AND "Higher Education" AND dropout rate)

TITLE-ABS-KEY (Rural AND "Higher Education" AND dropout)

TITLE-ABS-KEY (Rural AND "Higher Education" AND Drop-out)

TITLE-ABS-KEY (Rural AND "Higher Education" AND persistence)

TITLE-ABS-KEY (Rural AND "Tertiary Education" AND dropout rate)

TITLE-ABS-KEY (Rural AND "Tertiary Education" AND dropout)

TITLE-ABS-KEY (Rural AND undergraduate AND dropout)

TITLE-ABS-KEY (Rural AND undergraduate AND drop-out)

TITLE-ABS-KEY (Rural AND undergraduate AND persistence)

TITLE-ABS-KEY (Rural AND university OR Collage AND dropout rate)

TITLE-ABS-KEY (Rural AND university OR Collage AND dropout)

TITLE-ABS-KEY (Rural AND university OR Collage AND drop-out)

TITLE-ABS-KEY (Rural AND university OR collage AND "dropping out")

2

1

4

3

26

66

26

8

Note: The information search was conducted on March 25, 2021.

reviewed by peer reviewers and published under rigorous editorial processes (Schotten et al., 2017). Thus, the equations presented in Table 1 were used to determine the search for the documents. The search was conducted in English, as SCOPUS lists titles, abstracts, and keywords in that language. In addition, other filters were not used in the search for information such as: the period of publication, the geographical area of the study and the quartile of categorisation of the journals determined by SCOPUS. This was not considered relevant because previous empirical research (e.g., Byun et al., 2012; Guzmán et al., 2021) highlighted the lack of studies in a generalized manner, for that reason it was sought to include as many studies as possible with the purpose of avoiding the loss of information. In addition, the search for documents was limited to articles, books, book chapters and conference proceedings. On the other hand, for the selection of search keywords, reference to those used in previous systematic literature reviews was made such as Orellana et al. (2021), Guzmán et al. (2020a), Rodriguez Urrego (2019) and Kara et al. (2019), as well as recent empirical studies such as Guzmán et al. (2021), Behr et al. (2020), Kehm et al. (2019), Barragán and González (2017), as well as Vera et al. (2020).

As a result of the SCOPUS search, a total of 183 documents possibly related to the event of dropout in rural higher education were detected, which were registered in a database composed of the following data: type of document, year, authors, title of the document, journal, name of the book or conference proceedings, quartile of citation classification (only applied to journals), ISSN or ISBN, and keywords. From the documents found, a total of 69 were eliminated because they were duplicate records. Thus, with the remaining 114 records, the titles, abstracts, and keywords were read, with the intention of purging those documents not related to the topic of study, consolidating the documentary analysis sample consisting of 17 articles, one book chapter resulting from research and three conference proceedings. It is important to highlight that in the screening phase, and in order to eliminate bias in the selection of the documents, an independent review was carried out by each of the authors, evaluating the full text in the case of those documents in which the concepts were not unanimous. In addition, the PRISMA 2020 checklist was completed for each of the documents. Figure 2 shows the flow diagram of the PRISMA 2020 method.

\section{Stage Two: Analysis and Synthesis}

This stage sought to analyse and synthesise the findings to fulfil the objective of this article. In this way, two phases were carried out: the first was related to the bibliometric analysis of the documents included for review using descriptive statistics and data visualisation in accordance with the parameters established by Nightingale (2009). This phase sought to respond to RQ1. In this way, the country of origin in which the research was carried out, the frequency of publication per year, the categorisation of the articles according to SCOPUS ranking, methodologies used in the development of the studies, among others, were determined. The second phase corresponded to the content analysis of the documents, which answered RQ2, in which the explanatory variables of dropout in rural higher education were sought and associated with each of the determinants of the model described in Figure 1. Thus, each of the sample documents was loaded into the Atlas. ti software and the open coding technique was carried out, as it allows the researcher to establish categories or variables from the reading of the documents, so it is not limited to a pre-established theoretical framework, which results in the possibility of providing answers to questions of a general nature (Flick, 2012). After coding the variables, the findings were synthesised using an inductive approach.

\section{RESULTS}

\section{Bibliometric Analysis}

The review of the sample of papers showed that research had been carried out in ten countries of origin. Thus, seven papers related 
Identification of studies through databases and registers
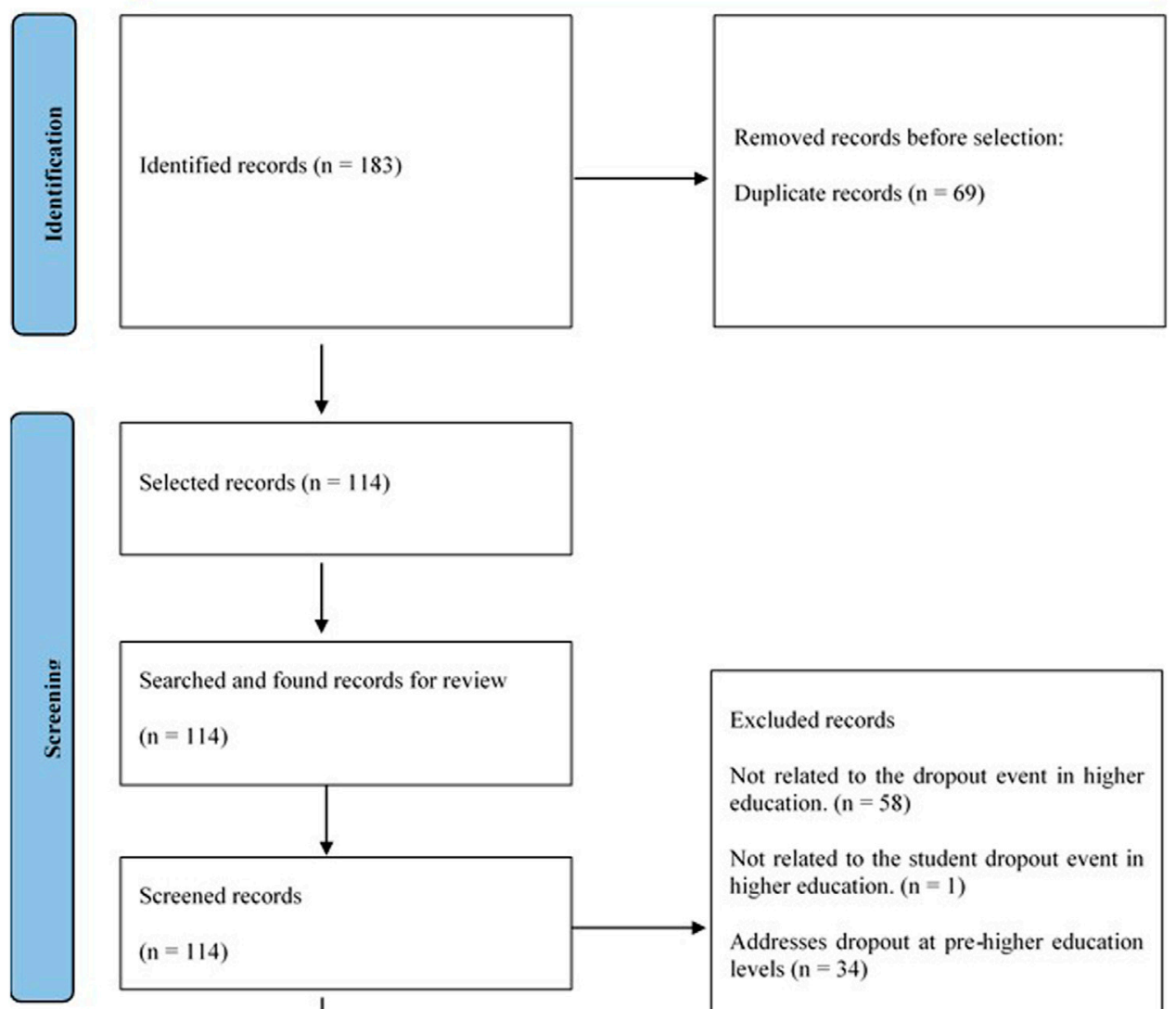

$$
\begin{aligned}
& \text { Searched and found records for review } \\
& (n=114)
\end{aligned}
$$

Excluded records

Not related to the dropout event in higher education. $(\mathrm{n}=58)$

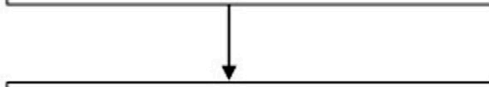

Not related to the student dropout event in

Screened records

$(n=114)$ higher education. $(\mathrm{n}=1)$

Addresses dropout at pre-higher education

levels $(\mathrm{n}=34)$
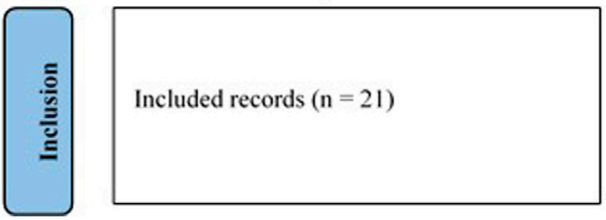

FIGURE 2 | PRISMA 2020 method flow chart. Adapted from (Page et al., 2021).

to rural people in higher education were published in the United States, two in Finland, two in Australia, and, in the case of Bangladesh, Brazil, China, Colombia, Ecuador, Norway and South Africa, one publication each. On the other hand, three of the papers in the sample did not specify the countries in which the research took place.

However, regarding the distribution of the sample by year of publication, no trend was evident, although it was observed that after 2010 the academic community's interest in the study of the event of dropout in the population under study at the higher level has grown, accounting for $52.38 \%$ of the documents analysed since that year (see Table 2 and Supplementary Figure S1).

In relation to the 19 published articles that are susceptible to categorisation by the SCOPUS indicators, only 18 of the sample had such categorisation. Of the categorised articles, $6.25 \%$ were in quartile one, $43.75 \%$ in quartile two, $31.25 \%$ in quartile three and $18.75 \%$ in quartile four. Table 2 summarises the papers in the sample, showing that by journal or conference there is no preference in the publication of research related to rural dropout at higher education level.

About the methodological approach used in previous research, it was found that $71.41 \%$ of the studies were characterised by a quantitative approach, $14.29 \%$ by a qualitative approach and $14.3 \%$ by a mixed approach. Thus, the quantitative studies, and as presented in Supplementary Table $\mathbf{S 1}$ there is a tendency to use the survey as the main data collection technique. In the case of qualitative studies, data collection techniques focus on interviews (in-depth or semi-structured), 
TABLE 2 | Documents in the sample under analysis.

\begin{tabular}{|c|c|c|c|}
\hline Code & $\begin{array}{c}\text { Authors and year } \\
\text { of publication }\end{array}$ & $\begin{array}{l}\text { Journal, book or } \\
\text { conference title }\end{array}$ & Quartile \\
\hline A1 & Bania and Kvernmo (2016) & International Journal of Circumpolar Health & Q2 \\
\hline $\mathrm{A} 2$ & Troester-Trate (2020) & Community College Journal of Research and Practice & Q2 \\
\hline $\mathrm{A} 3$ & Castleman and Meyer (2020) & Review of Higher Education & Q1 \\
\hline A4 & Gildehaus et al. (2019) & Innovative Higher Education & Q2 \\
\hline A5 & Hines et al. (2015) & Journal for Multicultural Education & Q4 \\
\hline A6 & Muñoz (2013) & Journal of Student Affairs Research and Practice & Q4 \\
\hline A7 & Rapley et al. (2008) & Nurse Education Today & Q2 \\
\hline A8 & Ramírez et al. (2020) & Revista de Psicología (Perú) & Q4 \\
\hline A9 & Nishat et al. (2020) & Journal of Applied Research in Higher Education & Q2 \\
\hline A10 & Pérez et al. (2019) & Educación Médica & Q3 \\
\hline A11 & Lewine et al. (2019) & Journal of College Student Retention: Research & Q2 \\
\hline A12 & De Hart and Venter (2013) & Perspectives in Education & Q3 \\
\hline A13 & Faizullina et al. (2013) & Medicina (Lithuania) & Q3 \\
\hline A14 & Rashid and Sarker (2008) & Turkish Online Journal of Distance Education & Q3 \\
\hline A15 & Pillay and Ngcobo. (2010) & South African Journal of Psychology & Q3 \\
\hline A16 & Wheat et al. (2003) & Journal of Rural Health & Q2 \\
\hline $\mathrm{A} 17$ & Warner (1993) & Distance Education & NA \\
\hline $\mathrm{C} 1$ & Oliveira et al. (2018) & Researcher Links Workshop: Higher Education for All & NA \\
\hline P1 & Qu (2009) & Proceedings of the International Symposium on Test and Measurement & NA \\
\hline $\mathrm{P} 2$ & Meisalo et al. (2003) & Frontiers in Education Conference & NA \\
\hline P3 & Meisalo et al. (2002) & Frontiers in Education Conference & NA \\
\hline
\end{tabular}

Note: code $A$ refers to articles, $C$ to chapters of books and $P$ to conferences proceedings. NA is not applicable.

focal groups and workshops, and finally, in mixed studies, both surveys, in-depth interviews and focal groups are used. Regarding the sample size, most of the studies are characterised by being relatively small in comparison to the country's population, and more specifically, those students linked to higher education in rural areas. Thus, only $29 \%$ of the studies had samples larger than 1,000 students, $62 \%$ had samples smaller than 1,000 students and $10 \%$, being academic experiences, did not reflect a sample in their methodological section.

\section{Variables Influencing Rural Student Dropout in Higher Education}

Corresponding to the model described in Figure 1, the results of previous research by determinant are presented below. In this sense, a total of 59 variables that have been the object of study were coded. Supplementary Table S2 presents the explanatory variables found in each of the documents. According to Supplementary Table S2, 35\% of the explanatory variables studied for dropout in rural higher education corresponded to the individual determinant, $27 \%$ to the academic, $25 \%$ to the socio-economic and $13 \%$ to the individual. Thus, in the case of the most studied variables of dropout in rural higher education in the studies analysed, they correspond to: 1 . the P\&GO programmes, this variable has been analysed in 10 case studies; 2 . Previous academic experience, being addressed in eight case studies; 3 . the state support, the family income and the labour obligations, each of these was analysed in five case studies.

However, the explanatory variables that were only identified once in the documents studied, were: adaptation to the HEI, selflearning, communication, course contents, family dysfunction, ethnicity, lack of job opportunities, academic failure, absences from classes, dissatisfaction with the programme, slow academic progress, Learning Management System, personal goals, fear of failure, motivation, death of relatives, parents' educational level, poverty, nutrition problems, scheduling problems, relationship problems with parents, racism, knowledge recognition, transfer to another university and use of ICTs.

\section{Individual Determinant}

With regards to the gender variable, it is evident in the documents analysed that rural women are more likely to drop out of higher education, a situation that has been constant over time, as evidenced by Meisalo et al. (2002) in a population of students in virtual programmes, as well as (De Hart and Venter, 2013) in face-to-face education. The latter authors emphasise that gender is a good predictor of rural students' intention to drop out of higher education because women tend to be more vulnerable as a result of housework and raising children, while men who drop out tend to do so because of work obligations or because they receive material in a second language, the last variable was analysed in the rural South African population, which is characterised by a large linguistic variety.

In relation to personal obligations represented in domestic and household chores, unemployed adults tend to drop out due to the need to provide basic goods and services to their houses, leading them to limit their spending to cover these needs, reducing or eliminating investments in education, so that if the chief member of the family or any of his relatives is the one who studies, he has to drop out, due to the economic insecurity that exists in rural areas (Nishat et al., 2020; De Hart and Venter, 2013). In the case of the work obligations of rural students, research generally agrees that the hours allocated to work compete with study hours. This was reflected by Pérez et al. (2019) when analysing the causes of 
desertion of a group of rural nursing students, where the greatest number of absences were due to work-related causes, affecting the academic average and influencing the student's decision to abandon their academic process. The same situation is described by (De Hart and Venter, 2013) in rural students employed in the finance sector. On the other hand, it has been established that having partial work obligations such as part-time or service jobs are related to sources of stress for the student as they do not secure sufficient resources to cover their educational and personal expenses, leading them to prioritise seeking fulltime employment and sacrificing their professional career (Pillay and Ngcobo, 2010).

In terms of age, research has indicated that both younger and older students located in or coming from rural areas are at risk of dropping out, however, the causes are different. In this regard, Pillay and Ngcobo (2010) identified that arguments and conflicts with and between parents led to young students not completing their academic process. On the other hand, (De Hart and Venter, 2013), established that, in developing countries, young students were the first generation to enter HEIs, so that support structures such as parents, close social references and HEIs' own support structures such as SATs and P\&GOs could fail to effectively address the counselling needs of those students. In the case of older students, it was observed that the main reason for dropping out of education was due to work and personal obligations (De Hart and Venter, 2013; Pillay and Ngcobo, 2010).

Following with the support structures, especially with parents, it became clear that the educational level of the parents is significantly related to the student's intention to continue their educational process. Bania and Kvernmo (2016) found that for rural women a higher level of parental education had an influence on the completion of pre-higher education, while for men the level of parental education was related to the completion of higher education. However, the same study argues that the educational level of parents does not have an impact on the completion of higher education among young students.

Another variable related to rural dropout in higher education is the ethnicity or social group to which the student belongs. In this sense, the language in which the study material is designed has a direct impact on the continuity of the academic process, as argued by (De Hart and Venter, 2013) in identifying this case in the Nguni community in South Africa, where unfamiliarity with the learner's culture is propitious to the materialisation of the event. Another phenomenon related to this variable is the racism that students from social groups that have historically been considered minorities may suffer at the educational level, as is the case of Afro-descendants in the United States or illegal immigrants, in which social pressure can lead to a process of demotivation and end up in desertion (Muñoz, 2013; Hines et al., 2015).

Regarding health as an explanatory variable of dropout, studies have focused on the psychological aspects of the student, finding that rural youth with behavioural problems tend to limit the number of years of study they take, which leads them to drop out of the education system or to choose less demanding training programmes, in which the risk of dropping out is greater for students who do not have behavioural problems
(Bania and Kvernmo, 2016). In this scenario, it should be recognised that male rural students with particular mental health conditions are more likely to fail to complete their training programme; this is related to the lack of search for HEI support structures (Bania and Kvernmo, 2016). In addition to what has been stated, Hines et al. (2015) found in their research that student mental health affects academic and social processes, being a determinant of non-completion of their studies.

What is more, it has been documented that rural students have a variety of difficulties in adapting to HEIs (Castleman and Meyer 2020). This is due to the change of educational environment involving commuting, creation of new personal relationships, conflict with the size of the educational institution and new academic demands, thus leading, in the words of Castleman and Meyer (2020), to a "shock" that may end in student dropout. This was exemplified in the study by Ramírez et al. (2020) in which they segmented rural students who dropped out of a Colombian university, and who had in common the lack of adaptation to the HEI as the main reason for the materialisation of the desertion event.

Regarding other variables, Ramírez et al. (2020) identified that the type of family can influence the non-continuation of the educational process. Students with single-parent or extended nuclear families (parents, siblings, grandparents and aunts and uncles who live together in the same house) have a greater risk of not concluding their educational process, as explained in the case of those students with work and personal obligations (Nishat et al., 2020) and in the case of the latter to sources of pressure and stress derived from the family environment (Pillay and Ngcobo, 2010). The death of family members or close relatives as an explanatory variable of dropout is related as a source of stress which, in conjunction with other psychological problems of the student, leads him/her to not complete the training process (Pillay and Ngcobo, 2010).

In relation to individual student variables related to the learning process, Meisalo et al. (2002) found an inversely proportional relationship between rural students' dropout and their attitude towards their academic process. Similarly, the lack of student autonomy in the development of academic activities, specifically in virtual programmes, was considered a persistent contributor to the occurrence of dropout (Meisalo et al., 2002), hence, P\&GOs focused on strengthening student autonomy in order to mitigate dropout rates in both virtual and face-to-face training programmes (Gildehaus et al., 2019). Similarly, rural students in the study developed by Lewine et al. (2019) showed higher levels of motivation leading them to complete their higher education studies, explaining this phenomenon in the equivalence of effort, thus stipulating a curvilinear hypothesis of resilience in those who face more obstacles in their higher education, as is the case of rural students, seek to have better results in their formative process due to the additional effort they have to do in order to stay linked to the HEI (Lewine et al., 2019). However, fear of failure can mitigate the resilience curve, especially in the first year of study (Pillay and Ngcobo, 2010). Finally, rural students' procrastination affects their academic performance and may lead them to drop out due to loss of purpose (Warner 1993). 


\section{Socioeconomic Determinant}

Regarding family income, research has shown that rural families are vulnerable compared to their urban counterparts, which makes this variable a predictor of student attendance at HEIs, as well as of dropout. Castleman and Meyer's work (2020) found that students tend to come from low-income families and adverse social backgrounds, which results in high drop-out rates due to the influence of variables such as work obligations, personal obligations and high costs associated with study. This was corroborated by Ramírez et al. (2020). In this context, and considering the family's economic difficulties, students often take part-time or full-time jobs to cover their personal and educational expenses, however, as related by Lewine et al. (2019) paradoxically this can generate conflicts because having an additional income, the family may begin to demand the student to share their money to cover non-academic expenses, which worsens the student's financial condition and may influence the student's dropout. Otherwise, if the student is unable to find a job or has lost his or her job for various reasons, he or she is more likely to drop out of school. (Muñoz, 2013; (De Hart and Venter, 2013). However, it is necessary to recognise that in countries where social asymmetries are not so marked, as is the case in the Nordic countries, or with efficient educational policies (e.g., free tuition). that allow rural students to be linked to the higher education subsystem, the results of studies indicate that family income does not have a significant impact on student permanence (Bania and Kvernmo, 2016).

On the other hand, low family income affects the student's experience at HEIs. Thus, Hines et al. (2015) noted that African American students from rural areas of the United States tended not to participate in pre- and extra-curricular paid activities which made it difficult for them to adapt to the higher education environment.

To compensate for the economic hardships faced by families, states have designed a series of public policies in the form of financial support that seek to eliminate the effect of these hardships in the event of dropout. Thus, the most common is related to the payment of tuition fees, either in the form of a scholarship or an educational credit (Lewine et al., 2019). In this way, the study by Qu (2009) showed through a mathematical model that this type of support is efficient in the rural population when the financing of tuition is close to or lower than the family's semester income, reducing the probability of dropping out, especially in the form of credit, while the opposite effect occurs when the cost of tuition is very high compared to the family's semester income. Despite the efforts of states to link state support to students based on their legal framework, not everyone can access this type of support, such as in the case of illegal migrants located in rural areas (Muñoz, 2013) or because of the student's lack of knowledge regarding access to this support due to a lack of information (Hines et al., 2015).

On the other hand, state support has only focused on economic aspects, which has meant that no other strategies have been developed to reduce dropout among rural students. An example of this was the study developed by (Rashid and Sarker, 2008) in which students who worked in state entities did not find it meaningful to finish their academic programme because it did not represent a better job position or economic income, hence the authors raised the suggestion to develop new supports not concentrated on academic level tuition.

In addition to the variables described above, it was identified that rural students have problems related to finding accommodation for their on-campus studies, due to the fact that HEIs are usually located far from rural areas and when institutions have student residences they do not prioritise this type of student (Pillay and Ngcobo, 2010), therefore, they are located on the outer periphery of cities where rent is usually cheaper, increasing their transport and mobilisation costs and longer distances, which results in the student's demotivation to continue their academic programme, as well as generating greater financial pressure for them and their families (Lewine et al., 2019). Similarly, rural students moving to urban areas often have nutrition problems, which is why some HEIs have developed food security plans, as expressed by Troester-Trate (2020).

\section{Academic Determinant}

Findings related to previous academic experience can be divided into two subcategories. The first concerns the academic performance of rural students at pre-higher education levels, where a relationship has been widely established between academic performance and higher education performance in terms of average grades (Bania and Kvernmo, 2016). As such, students who are better qualified in secondary school have a lower risk of dropping out at the tertiary level (Rapley et al., 2008; Faizullina et al., 2013; Hines et al., 2015; Lewine et al., 2019; De Hart and Venter, 2013), as well as those with high performance in specific subjects, as was the case for natural sciences in the medical school students analysed in the study by Faizullina et al. (2013). The second subcategory is related to disciplinary knowledge prior to the training programme, where student desertion in the rural population is directly related to the knowledge acquired in secondary school in specific undergraduate subjects. This was evidenced in the work of Meisalo et al. (2003) and Meisalo et al. (2002) in a group of engineering students, where those who had never seen programming ended their training process early.

However, with regard to the social capital acquired by rural students through their family and relatives, the literature has established that this capital is usually low due to the fact that they are the first generation to enter an HEI (Castleman and Meyer, 2020), this has repercussions on various academic aspects such as performance in the absence of a rigid support structure (Hines et al., 2015; Castleman and Meyer, 2020), or on motivational aspects (Hines et al., 2015) that can lead to students dropping out of the training programme. In line with the above, rural students often have difficulties in learning due to poor academic performance at previous levels and the lack of specialised support structures for them. That said, Meisalo et al. (2002) found in a rural population in Finland that the complexity of programming course content in an engineering faculty, combined with problems of student comprehension, led to the dropout of part of the student population in the first year of training. Similarly, Nishat et al. (2020) found that class difficulty 
expressed in content is often one of the reasons why rural students drop out.

Regarding university average for rural students, research by Castleman and Meyer (2020), Lewine et al. (2019), Meisalo et al. (2003), Meisalo et al. (2002) found that the higher the university average, the lower the likelihood of dropout. However, Castleman and Meyer (2020) noted that students in rural areas tend to enrol for fewer academic credits, which represents a lower number of courses taken per semester, resulting in a lower probability of timely graduation. On the other hand, Nishat et al. (2020) recognise that GPA can be positively influenced by $P \& G O$ when the student actively participates in additional tutoring and other services provided by these types of programmes within HEIs.

In relation to other variables, the selection of the training programme has a direct impact on rural student desertion, given that a poor choice results in a lack of motivation to continue their training process, leading them to drop out of the programme (Pillay and Ngcobo, 2010; Nishat et al., 2020). This is due to a lack of information prior to the selection of the academic programme or family pressures (Pillay and Ngcobo, 2010). Faizullina et al. (2013) reported that this variable is one of the main causes of dropout in medical schools in Kazakhstan. On the other hand, excessive academic work can lead to the phenomenon of dropout, as it competes in time with other student activities such as work and personal obligations imposed by their socioeconomic reality (Pillay and Ngcobo, 2010; Pérez et al., 2021). In addition, some of the academic activities are not adjusted to the realities of rural students, such as the use of hardware, software, and internet to which rural students often do not have access (Meisalo et al., 2002; Pérez et al., 2019).

On the other hand, the size of the school from which students graduated has an impact on dropout in the rural population, as observed by Wheat et al. (2003); students from small schools tended to leave school early. This is explained by Pillay and Ngcobo (2010) who point out that teachers in rural schools tend to have less training than urban teachers, and that the subjects taught do not cover the whole curriculum, which puts rural students at a disadvantage when entering HEIs and can lead to problems with students' academic progress (Warner, 1993). Finally, absence from class due to problems with work obligations or long commutes, as well as the crossing of subject timetables, can lead to students dropping out (Ramírez et al., 2020).

\section{Institutional Determinant}

The P\&GO programmes have become one of the central axes to prevent and mitigate the dropout of rural students by HEIs. Thus, Warner (1993) identified how these programmes strengthen the student's self-learning skills and autonomy to carry out their training process, which according to the author helps to reduce dropout rates. Similarly, Nishat et al. (2020) found that these programmes not only strengthened students' specific skills, but also significantly increased their GPA compared to students who did not participate in these programmes. However, the opposite effect was recorded for students who did not participate in such programmes. This may be due to a lack of student interest in participating, or to the limitations of these programmes in HEIs, which may define activities that do not fit the profile of the rural student (Castleman and Meyer, 2020), or have limited channels of communication and participation (Meisalo et al., 2002). However, positive results are not achieved in all areas, as demonstrated by Troester-Trate (2020) in which activities developed in P\&GO programmes such as the assisted meal plans did not have an impact on student retention in HEIs. Finally, and because of the evolution of information and communication technologies in the framework of this type of programme, multiple software applications have been implemented in favour of student retention. This is reflected in the work of Oliveira et al. (2018) who documented the use of the mobile application "MobilMonitor", in addition to the use of SAT in the Learning Management System to identify students in rural areas, in a Brazilian state, who require individualised pedagogical support to make an early intervention and achieve their permanence.

In terms of communication between rural students and HEIs, the diversification of channels allows for permanence and retention, as described in Castleman and Meyer's work (2020) in which the use of text messages was implemented in order to inform students about administrative and academic procedures to be carried out before and during the semester of study. On the other hand, in the case of virtual programmes, the absence of communication with the teacher is a predictor of desertion, since, as this academic model is based on self-learning, contact would be expected to focus on reinforcing the contents and clarifying doubts, hence HEIs with this type of training programmes seek various channels to facilitate communication between the teacher and the student (Meisalo et al., 2002).

In terms of content language, some HEIs neglect the linguistic variety of rural students, especially in developing countries, which hampers the learning process (Rashid and Sarker, 2008). Additionally, the requirement of a second language as a graduation requirement creates difficulties for some rural students, due to the limited competences developed at previous academic levels (De Hart and Venter, 2013; Rashid and Sarker, 2008). Finally, it was found that the recognition of knowledge acquired by students at previous educational levels or through work experience by HEIs encourages academic retention (Bania and Kvernmo, 2016).

\section{DISCUSSION AND CONCLUSION}

As presented in the results section, based on the systematic review, important findings were made about dropout in rural higher education. The first relates to the countries that have led research on this event in the rural student population, where the United States, Finland, Australia, and Norway stand out, which shows the interest of developed countries in understanding and determining the causes of non-continuation of studies in the rural population, and, to a lesser extent, in developing countries. In this sense, it should be noted that the results of these studies are not generalisable, since, beyond the size of the sample, in which it is evident that most of the studies are characterised by very small 
samples (see Supplementary Table S1), such as Troester-Trate (2020), Gildehaus et al. (2019), Hines et al. (2015), among others; or, the type of study, there are strong social asymmetries between the economies of developing countries, which may render the findings meaningless outside the context in which the research was carried out, as stated by Guzmán et al. (2021). On the other hand, after searching for documents in SCOPUS it was determined that dropout in the rural student population has not been of great interest to academic actors, despite the growing number of publications since 2010, as evidenced by the limited number of studies found in the period from 1993 to 2020, and that, in comparison with other systematic reviews that addressed various perspectives of dropout and where the period of analysis was shorter than the present study, fewer documents were found, as presented in the reviews by (Orellana et al., 2021) $(n=72)$ and (Guzmán et al., 2020b) ( $n=31)$.

The second finding concerns the variables that have been studied in the framework of determinants, in which, of the 55 variables coded, $35 \%$ corresponded to the individual, $25 \%$ to the socioeconomic, $27 \%$ to the academic and $13 \%$ to the institutional. Having said that, the studies that made up the sample concentrated their main interest on the explanatory variables of the individual and academic determinants. Moreover, the multi-causality of dropout in the rural population is recognised, since its explanation is derived from the influence of multiple variables which influence those that make up the same determinant or those of others, as was detected in the case of the variables of gender, age, work obligations, personal obligations, family income, ethnicity or social group, state support, among others. This is in line with the theoretical approach proposed in this article (see Figure 1) and which has been used in previous research such as those developed by Guzmán et al. (2021), Kemper et al. (2020) and Barragán and González (2017). On the other hand, it is necessary to recognise that there are variables that have been analysed in rural populations and not so intensively in other student populations in higher education, such as: cultural context, family dysfunction, ethnicity, the language of content, death of relatives, nutritional problems, racism, and migration status.

However, due to the limited number of studies identified in the high-impact literature related to dropout in rural higher education, there are future lines of research that can be addressed to establish explanatory or predictive models that account for the causes and high rates that occur in the rural population at the higher education level. An example of this is the study of the variables and causes that lead rural students in virtual mode to drop out, since the studies found are more than a decade old, in discordance with the evolution of this educational modality, in addition to its consolidation as one of the possibilities for access to higher education for the rural student population within the framework of public policies (Guzmán et al., 2021); or, the study of variables identified in other contexts that may influence dropout at higher education level in the rural student population, and which have not been analysed, such as: armed conflict and the legal status of students (Muñoz, 2013), the effectiveness of financial support (Qayyum et al., 2019), learning preferences (Aragon and Johnson, 2008), the level of student resilience (Packham et al., 2004), commitment to the academic goal (Choi and Kim, 2018; Morris and Finnegan, 2008), level of engagement in pedagogical teaching strategies and classroom learning (Choi and kim, 2018).

Finally, both the results presented in this article and their discussion should be understood within the manifest scope of the study, such as the search limited to SCOPUS which, although it lists high-impact literature, it is necessary for future reviews to include other databases and search engines in which other documents can be found to enrich the analysis of the identified variables that indicate student dropout in rural higher education. On the other hand, the systematic review showed the relevance of prospective work on mathematical and statistical modelling that links the variables together, detecting the direct and indirect influence of the variables on the decision to drop out or persist in higher education and identifying intermediate variables that affect permanence in the education system and whose consequences are slow to manifest themselves. However, other limitations related to the method selected for the literature review include the heterogeneity of studies, the inductive analysis carried out in each of the documents, among others.

Consequently, the objective of this article was achieved, which was to identify the individual, socioeconomic, academic, and institutional explanatory variables involved in student dropout in rural populations, based on a synthesis of the evidence available in the SCOPUS database. A complementary contribution of this article is to provide a comprehensive view of dropout in the rural student population at the higher education level, which constitutes an advance for the strengthening of public and private policies of HEIs in order to prevent and mitigate the event in an effective and efficient manner, and thus consolidate the tangible and intangible benefits of higher education in the rural student population.

\section{DATA AVAILABILITY STATEMENT}

The original contributions presented in the study are included in the Supplementary Material. The Supplementary Material, further inquiries can be directed to the corresponding author.

\section{AUTHOR CONTRIBUTIONS}

AG and SB contributed to conception and design of the study. AG organized the database. AG performed quantitative and qualitative analysis. $\mathrm{AG}$ and $\mathrm{SB}$ wrote the first draft of the manuscript. AG, SB and FCV reviewed and edited. SB and FCV supervised both the development of the research and the manuscript. All authors contributed to manuscript revision, read, and approved the submitted version. 


\section{ACKNOWLEDGMENTS}

The University Corporation of Asturias, whose support covered the cost of the publication, and to Cecilia Carabajal who, with her unconditional support, made the style correction and translation of this article.

\section{REFERENCES}

Adrogue, C., and García de Fanelli, A. M. (2018). Gaps in Persistence under OpenAccess and Tuition-free Public Higher Education Policies. epaa 26, 126. doi:10.14507/epaa.26.3497

Alkan, N. (2014). Humor, Loneliness and Acceptance: Predictors of University Drop-Out Intentions. Proced. - Soc. Behav. Sci. 152, 1079-1086. doi:10.1016/ j.sbspro.2014.09.278

Alfa Guia Project DCI-ALA/2010/94; Alfa Guia Project DCI-ALA/2010/94 (2013). Estudio sobre Políticas Nacionales sobre el abandono en la Educación Superior en los países que participan en el Proyecto ALFAGUIA. ALFA GUIA DCI-ALA/2010/94. Madrid: Gestión Universitaria Integral del Abandono.

Aragon, S. R., and Johnson, E. S. (2008). Factors Influencing Completion and Noncompletion of Community College Online Courses. American Journal of Distance Education 22, 146-158. doi:10.1080/08923640802239962

Arias-Velandia, N., Rincón-Báez, W. U., and Cruz-Pulido, J. M. (2018). DESEMPEÑO DE MUJERES Y HOMBRES EN EDUCACIÓN SUPERIOR PRESENCIAL, VIRTUAL Y A DISTANCIA EN COLOMBIA - Women and Men Performance in Face-To-Face, Virtual and Distance Higher Education in Colombia. pnrm 12, 57-69. doi:10.15765/pnrm.v12i22.1142

Armstrong, S. N., Early, J. O., Burcin, M. M., Bolin, K., Holland, N., and No, S. (2018). New Media Tools Impact on Online, Health Science Students' Academic Persistence and Support: Lessons Learned from Two Pilot Studies. TechTrends 62, 266-275. doi:10.1007/s11528-018-0261-1

Bania, E. V., and Kvernmo, S. E. (2016). Tertiary Education and its Association with Mental Health Indicators and Educational Factors Among Arctic Young Adults: the NAAHS Cohort Study. Int. J. Circumpolar Health 75, 32086. doi:10.3402/ijch.v75.32086

Barragán Moreno, S. P., and González Támara, L. (2017). Acercamiento a la deserción estudiantil desde la integración social y académica. Revista de la Educación Superior 46, 63-86. doi:10.1016/j.resu.2017.05.004

Barragán, S., and Rodríguez, R. B. (2015). "Diagnóstico y seguimiento de la deserción en la Universidad de Bogotá Jorge Tadeo Lozano," in La Universidad de Bogotá Jorge Tadeo Lozano en el camino de la retención estudiantil. Más Cerca de la reducción del abandono estudiantil en la Tadeo (Bogota: Universidad de Bogotá Jorge Tadeo Lozano), 62-63.

Bean, J. P. (1986). Assessing and Reducing Attrition. New Dir. Higher Education 1986, 47-61. doi:10.1002/he.36919865306

Becerra, M., Alonso, J. D., Frias, M., Angel-Urdinola, D., and Vergara, S. (2020). Latin America and the Caribbean: Tertiary Education. Available at: https://documents1. worldbank.org/curated/en/720271590700883381/COVID-19-Impact-on-TertiaryEducation-in-Latin-America-and-the-Caribbean.pdf.

Behr, A., Giese, M., Teguim Kamdjou, H. D., and Theune, K. (2020). Dropping Out of university: a Literature Review. Rev. Educ. 8, 614-652. doi:10.1002/rev3.3202

Broadbent, J., and Poon, W. L. (2015). Self-regulated Learning Strategies \& Academic Achievement in Online Higher Education Learning Environments: A Systematic Review. Internet Higher Education 27, 1-13. doi:10.1016/j.iheduc.2015.04.007

Byun, S. Y., Irvin, M. J., and Meece, J. L. (2012). Predictors of Bachelor's Degree Completion Among Rural Students at Four-Year Institutions. Rev. High Ed. 35, 463-484. doi:10.1353/rhe.2012.0023

Castleman, B. L., and Meyer, K. E. (2020). Can Text Message Nudges Improve Academic Outcomes in College? Evidence from a West Virginia Initiative. Rev. Higher Education 43, 1125-1165. doi:10.1353/rhe.2020.0015

Chalfin, A., and Deza, M. (2019). The Intergenerational Effects of Education on Delinquency. J. Econ. Behav. Organ. 159, 553-571. doi:10.1016/ j.jebo.2017.07.034

\section{SUPPLEMENTARY MATERIAL}

The Supplementary Material for this article can be found online at: https://www.frontiersin.org/articles/10.3389/feduc.2021.727833/ full\#supplementary-material

Choi, H. J., and Kim, B. U. (2018). Factors Affecting Adult Student Dropout Rates in the Korean Cyber-University Degree Programs. J. Continuing Higher Education 66, 1-12. doi:10.1080/07377363.2017.1400357

Contreras, C. (2018). Rendimiento académico de los alumnos de último año de Licenciaturas presenciales e Ingeniería de la Facultad Multidisciplinaria de Ilobasco durante el ciclo I - 2017. Anuario de Investigación 7, 125-139. Available at: http://localhost:80/xmlui/handle/123456789/217 (Accessed March 28, 2021).

Cristia, J., and Pulido, J. (2020). "Education in Latin America and the Caribbean: Segregated and Unequal," in The Inequality Crisis: Latin America and the Caribbean At the Crossroad. Editor M. Busso and J. Messina (Washington D.C: Busso and Messina), 166-193.

De Hart, K., and Venter, J. M. P. (2013). Comparison of Urban and Rural Dropout Rates of Distance Students. Perspect. Education 31, 66-76. Available at: https:// www.ajol.info/index.php/pie/article/view/87989 (Accessed May 28, 2021).

Donoso, S., and Schiefelbein, E. (2007). Análisis De Los Modelos Explicativos De Retención De Estudiantes En La Universidad: Una Visión Desde La Desigualdad Social. Estudios Pedagógicos XXXIII, 7-27. Available at: https:// www.redalyc.org/articulo.oa?id=173514133001 (Accessed May 28, 2021).

Ethington, C. A. (1990). A Psychological Model of Student Persistence. Res. High Educ. 31, 279-293. doi:10.1007/BF00992313

Faizullina, K., Kausova, G., Kalmataeva, Z., Nurbakyt, A., and Buzdaeva, S. (2013). Career Intentions and Dropout Causes Among Medical Students in Kazakhstan. Medicina (Kaunas) 49, 284-290. doi:10.3390/medicina49060045

Fishbein, M., and Ajzen, I. (1975). Belief, Attitude, Intention, and Behavior: An Introduction to Theory and Research. 1st ed. Reading: Addison-Wesley.

Flick, U. (2012). Introducción a la Investigación Cualitativa. Madird: Ediciones Morata.

Fonseca, G., and García, F. (2016). Permanencia y abandono de estudios en estudiantes universitarios: un análisis desde la teoría organizacional. Revista de la Educación Superior 45, 25-39. doi:10.1016/j.resu.2016.06.004

Ghignoni, E. (2017). Family Background and university Dropouts during the Crisis: the Case of Italy. High Educ. 73, 127-151. doi:10.1007/s10734-0160004-1

Gibbs, R. M. (1998). "College Completion and Return Migration Among Rural Youth, " in Rural Education and Training in the New Economy: The Myth of the Rural Skills gap. Editors P. L. Swaim and R. Teixeira (Teixeira (Iowa: USA: Iowa State University Press), 61-80.

Gildehaus, L., Cotter, P., Buck, S., Sousa, M., Hueffer, K., and Reynolds, A. (2019). The Research, Advising, and Mentoring Professional: a Unique Approach to Supporting Underrepresented Students in Biomedical Research. Innov. High Educ. 44, 119-131. doi:10.1007/s10755-018-9452-0

Guzmán, A., Quecano, L. I., Segovia- García, N., and Rodríguez-Cánovas, B. (2020a). “"Abandono estudiantil en Educación Superior y su relación con la comunicación en programas de modalidad virtual: Colombia,"," in La comunicación especializada del siglo (McGraw-Hill Interamericana de España), XXI, 939-957.

Guzmán, A., Valencia, L. I., Moreno, W., and Segovia, N. (2020b). ““Factores prematricula asociados a la deserción en educación superior en modalidad virtual: una revisión sistematizada,"," in Inclusión, Tecnología y Sociedad: investigación e innovación en educación (Madrid: Dykinson, 784-794.

Guzmán Rincón, A., Barragán, S., and Cala Vitery, F. (2021). Rurality and Dropout in Virtual Higher Education Programmes in Colombia. Sustainability 13, 4953. doi:10.3390/su13094953

Hällsten, M. (2017). Is Education a Risky Investment? the Scarring Effect of University Dropout in Sweden. Eur. Sociol. Rev. 33, 169-181. doi:10.1093/esr/ jcw053

Heidrich, L., Victória Barbosa, J. L., Cambruzzi, W., Rigo, S. J., Martins, M. G., and dos Santos, R. B. S. (2018). Diagnosis of Learner Dropout Based on Learning 
Styles for Online Distance Learning. Telematics Inform. 35, 1593-1606. doi:10.1016/j.tele.2018.04.007

Heublein, U., Hutzsch, C., Schreiber, J., Sommer, D., and Besuch, G. (2010). Ursachen des Studienabbruchs in Bachelor-und herkömmlichen Studiengängen: Ergebnisse einer bundesweiten Befragung von Exmatrikulierten des Studienjahres 2007/2008 [Causes for dropout in bachelor and traditional study programmes. Results of a national survey of exmatriculated students of the academic year 2007/2008]. 1st ed.. Berlin: Germany.

Hines, E. M., Borders, L. D., and Gonzalez, L. M. (2015). "It Takes Fire to Make Steel". J. Multicultural Education 9, 225-247. doi:10.1108/JME-01-2015-0001

Jeno, L. M., Danielsen, A. G., and Raaheim, A. (2018). A Prospective Investigation of Students' Academic Achievement and Dropout in Higher Education: a SelfDetermination Theory Approach. Educ. Psychol. 38, 1163-1184. doi:10.1080/ 01443410.2018 .1502412

Kara, M., Erdoğdu, F., Kokoç, M., and Cagiltay, K. (2019). Challenges Faced by Adult Learners in Online Distance Education: A Literature Review. openpraxis 11, 5. doi:10.5944/openpraxis.11.1.929

Kehm, B. M., Larsen, M. R., and Sommersel, H. B. (2019). Student Dropout from Universities in Europe: A Review of Empirical Literature. HERJ 9, 147-164. doi:10.1556/063.9.2019.1.18

Kemper, L., Vorhoff, G., and Wigger, B. U. (2020). Predicting Student Dropout: A Machine Learning Approach. Eur. J. Higher Education 10, 28-47. doi:10.1080/ 21568235.2020.1718520

Kilian, P., Loose, F., and Kelava, A. (2020). Predicting Math Student Success in the Initial Phase of College with Sparse Information Using Approaches from Statistical Learning. Front. Educ. 5, 502698. doi:10.3389/feduc.2020.502698

Klein, D. (2019). Das Zusammenspiel zwischen akademischer und sozialer Integration bei der Erklärung von Studienabbruchintentionen. Eine empirische Anwendung von Tintos Integrationsmodell im deutschen Kontext. Z. Erziehungswiss 22, 301-323. doi:10.1007/s11618-018-0852-9

Lance, L. (2011). Nonproduction Benefits of Education in Handbook of the Economics of Education(Amsterdam: Elsevier), 182-282. doi:10.1016/B978-0444-53444-6.00002-X

Lázaro Alvarez, N., Callejas, Z., and Griol, D. (2020). Factores que inciden en la deserción estudiantil en carreras de perfil Ingeniería Informática. revistafuentes 1, 105-126. doi:10.12795/revistafuentes.2020.v22.i1.09

Lewine, R., Manley, K., Bailey, G., Warnecke, A., Davis, D., and Sommers, A. (2019). College Success Among Students from Disadvantaged Backgrounds: "Poor" and "Rural" Do Not Spell Failure. J. Coll. Student Retention: Res. Theor. Pract. 152102511986843, 152102511986843. doi:10.1177/1521025119868438

Marquez-Vera, C., Morales, C. R., and Soto, S. V. (2013). Predicting School Failure and Dropout by Using Data Mining Techniques R. IEEE R. Iberoamericana Tecnologias Aprendizaje 8, 7-14. doi:10.1109/rita.2013.2244695

Meisalo, V., Sutinen, E., and Torvinen, S. (2003). Choosing Appropriate Methods for Evaluating and Improving the Learning Process in Distance Programming Courses. 33rd ASEE/IEEE Frontiers in Education ConferenceBoulder. IEEE, 11-16.

Meisalo, V., Sutinen, E., and Torvinen, S. (2002). How to Improve a Virtual Programming Course? 32nd Annual Frontiers in Education. Boston, MA, USA. IEEE, T2G-T11-T2G-16. doi:10.1109/FIE.2002.1157951

Migali, G., and Zucchelli, E. (2017). Personality Traits, Forgone Health Care and High School Dropout: Evidence from US Adolescents. J. Econ. Psychol. 62, 98-119. doi:10.1016/j.joep.2017.06.007

Ministry of National Education (2009). Deserción estudiantil en la educación superior colombiana: Metodología de seguimiento, diagnóstico y elementos para su prevención. 1st ed. Bogotá: Colombia: Ministry of National Education.

Moreno, W., Segovia, N., Grillo, C., Dworaczek, H. O., and Coy, H. V. (2019). "“Naturaleza del endeudamiento como base de la propuesta de política pública para la educación superior en Colombia desde 2013," in Innovación Docente e Investigación en Ciencias Sociales, Económicas y Jurídicas (Madrid: Dykinson), $25-36$

Morris, L. V., Wu, S.-S., and Finnegan, C. L. (2005). Predicting Retention in Online General Education Courses. American Journal of Distance Education 19, 23-36. doi:10.1207/s15389286ajde1901_3

Muñoz, S. M. (2013). "I Just Can't Stand Being like This Anymore": Dilemmas, Stressors, and Motivators for Undocumented Mexican Women in Higher Education. J. Student Aff. Res. Pract. 50, 233-249. doi:10.1515/jsarp-2013-0018

Nightingale, A. (2009). A Guide to Systematic Literature Reviews. Surgery (Oxford) 27, 381-384. doi:10.1016/j.mpsur.2009.07.005
Nishat, N., Islam, Y. M., BiplobMd, K. B. M. B. B., Mustain, U., and Hossain, M. K. (2020). Empowering Tertiary Level Students to Solve Their Own Study-Related Problems to Improve Study Performance. JARHE 12, 1117-1133. doi:10.1108/ JARHE-07-2018-0136

OECD (2018). Tertiary Graduation Rate. doi:10.1787/15c523d3-en

Oliveira, E. H. T., Carvalho, J. R. H., Oliveira, H. A. B. F., Gadelha, B. F., Lucena, K. T., Ramos, D. B., et al. (2018). Higher Education in the Amazon: Challenges and Initiatives Higher Education for All. From Challenges to Novel Technology-Enhanced Solutions. Editors A. I. Cristea, I. I. Bittencourt, and F. Lima (Cham: Springer International Publishing), 17-31. doi:10.1007/9783-319-97934-2_2

Orellana, D., Segovia, N., and Cánovas, B. R. (2020). El abandono estudiantil en programas de educación superior virtual: revisión de literatura. Revista de la Educación Superior 49, 45-62. Available at: http://resu.anuies.mx/ojs/index. $\mathrm{php} / \mathrm{resu} /$ article/view/1124 (Accessed May 28, 2021).

Ortíz, E. A., and Dehon, C. (2013). Roads to Success in the Belgian French Community's Higher Education System: Predictors of Dropout and Degree Completion at the Université Libre de Bruxelles. Research in Higher Education 54, 693-723. doi:10.1007/s11162-013-9290-y

Packham, G., Jones, P., Miller, C., and Thomas, B. (2004). E-learning and retention: key factors influencing student withdrawal. Education Training 46, 335-342. doi:10.1108/00400910410555240

Page, M. J., McKenzie, J. E., Bossuyt, P. M., Boutron, I., Hoffmann, T. C., Mulrow, C. D., et al. (2021). The PRISMA 2020 Statement: an Updated Guideline for Reporting Systematic Reviews. Syst. Rev. 10, 89. doi:10.1186/s13643-02101626-4

Palacio Sprockel, L. E., Vargas Babilonia, J. D., and Monroy Toro, S. L. (2020). Análisis bibliométrico de estudios sobre factores socioeconómicos en estudiantes universitarios. Educ. Educ. 23, 355-375. doi:10.5294/ edu.2020.23.3.1

Pérez, A. M., Escobar, C. R., Toledo, M. R., Gutierrez, L. B., and Reyes, G. M. (2018). Modelo de predicción de la deserción estudiantil de primer año en la Universidad Bernardo O 'Higgins. Educaçao e Pesquisa: Revista da Faculdade de Educação da Universidade de São Paulo 44, 86. Available at https://dialnet. unirioja.es/servlet/articulo?codigo $=7315140$ (Accessed May 27, 2021).

Pérez Cardoso, C. N., Cerón Mendoza, E. A., Suárez Mella, R. P., Mera Martínez, M. E., Briones Bermeo, N. P., Zambrano Loor, L. Y., et al. (2019). Deserción y repitencia en estudiantes de la carrera de Enfermería matriculados en el período 2010-2015. Universidad Técnica de Manabí. Ecuador. 2017. Educación Médica 20, 84-90. doi:10.1016/j.edumed.2017.12.013

Pillay, A. L., and Ngcobo, H. S. B. (2010). Sources of Stress and Support Among Rural-Based First-Year University Students: An Exploratory Study. South Afr. J. Psychol. 40, 234-240. doi:10.1177/008124631004000302

Qayyum, A., Zipf, S., and Dillon, J. M. (2019). Financial aid and student persistence in online education in the United States. Distance Education 40, 20-31. doi:10.1080/01587919.2018.1553561

Qu, Y. (2009). Research and Application of Diversified Model in Yardstick of Higher Education Tuition. In 2009 International Conference on Test and Measurement, 319-322. doi:10.1109/ICTM.2009.5413043

Rashid, A. Q. M. B., and Sarker, M. S. A. (2008). Strategic Intervention of ODL in Diploma in Youth Development Works in Bangladesh. Turkish Online J. Distance Education 9, 89-96. Available at: https://eric. Accessed May 28, 2021.

Radovan, M. (2019). Should I Stay, or Should I Go? Revisiting Student Retention Models in Distance Education. Turkish Online J. Distance Education, 29-40. doi:10.17718/tojde.598211

Rapley, P., Davidson, L., Nathan, P., and Dhaliwal, S. S. (2008). Enrolled Nurse to Registered Nurse: Is There a Link between Initial Educational Preparation and Course Completion? Nurse Educ. Today 28, 115-119. doi:10.1016/ j.nedt.2007.03.006

Rodríguez Urrego, M. (2019). La investigación sobre deserción universitaria en Colombia 2006-2016. Tendencias y resultados. Pedagog. Saberes. doi:10.17227/ pys.num51-8664

Rueda Ramírez, S. M., Urrego Velásquez, D., Páez Zapata, E., Velásquez, C., and Hernández Ramírez, E. M. (2020). Perfiles de riesgo de deserción en estudiantes de las sedes de una universidad colombiana. Psico 38, 275-297. doi:10.18800/ psico.202001.011

Schmitt, J., Fini, M. I., Bailer, C., Fritsch, R., and Andradede, D. F. d. (2020). WWH-dropout Scale: when, Why and How to Measure Propensity to Drop 
Out of Undergraduate Courses. Jarhe 13, 540-560. doi:10.1108/JARHE-012020-0019

Schotten, M., el Aisati, M. h., Meester, W. J. N., Steiginga, S., and Ross, C. A. (2017). "A Brief History of Scopus: The World's Largest Abstract and Citation Database of Scientific Literature," in Research Analytics. Editor F. J. Cantú-Ortiz (New York: Taylor \& Francis Group), 31-58. doi:10.1201/9781315155890-3

Segovia-García, N., and Said-Hung, E. (2021). Factores de satisfacción de los alumnos en e-learning en Colombia. Revista Mexicana de Investigación Educativa 26, 595-621.

Snyder, T. D., and Dillow, S. A. (2010). Digest of Education Statistics, 2009. NCES 2010-013. National Center for Education Statistics. Available at: https://eric (Accessed March 28, 2021).

Sosu, E. M., and Pheunpha, P. (2019). Trajectory of University Dropout: Investigating the Cumulative Effect of Academic Vulnerability and Proximity to Family Support. Front. Educ., 4, 6. doi:10.3389/feduc.2019.00006

Spady, W. G. (1970). Dropouts from Higher Education: An Interdisciplinary Review and Synthesis. Interchange 1, 64-85. doi:10.1007/BF02214313

The World Bank (2017). At a Crossroads Higher Education in Latin America and the Caribbean Washington D.C. The World Bank .

Tinto, V. (1987). Leaving College: Rethinking the Causes and Cures of Student Attrition. 1st ed. Chicago: USA: University of Chicago Press.

Tinto, V. (1975). Dropout from Higher Education: A Theoretical Synthesis of Recent Research. Rev. Educ. Res. 45, 89-125. doi:10.3102/ 00346543045001089

Tinton, V., and Cullen, J. (1973). Dropout in Higher Education: a Review and Theoretical Synthesis of Recent Research. Available at: https://files.eric.

Troester-Trate, K. E. (2020). Food Insecurity, Inadequate Childcare, \& Transportation Disadvantage: Student Retention and Persistence of Community College Students. Community Coll. J. Res. Pract. 44, 608-622. doi:10.1080/10668926.2019.1627956

UNESCO. (2020). Education post-COVID-19: Extraordinary Session of the Global Education Meeting (2020 GEM). New York: UNESCO. Available at: https://en.unesco.org/sites/default/files/gem2020-extraordinarysession-background-document-en.pdf (Accessed February 15, 2021).
Venegas-Muggli, J. I. (2020). Higher Education Dropout of Non-traditional Mature Freshmen: the Role of Sociodemographic Characteristics. Stud. Continuing Education 42, 316-332. doi:10.1080/0158037X.2019.1652157

Vera Cala, L. M., Niño García, J. A., Porras Saldarriaga, A. M., Durán Sandoval, J. N., Delgado Chávez, P. A., Caballero Badillo, M. C., et al. (2020). Salud mental y deserción en una población universitaria con bajo rendimiento académico. Rev.virtual Univ. Catol. Norte, 137-158. doi:10.35575/ rvucn.n60a8

Voelkle, M. C., and Sander, N. (2008). University Dropout. J. Individual Differences 29, 134-147. doi:10.1027/1614-0001.29.3.134

Warner, L. (1993). WIST - A Science and Technology Access Programme for Rural Women: The Determinants of success. Distance Education 14, 85-96. doi:10.1080/0158791930140107

Wheat, J. R., Brandon, J. E., Carter, L. R., Leeper, J. D., and Jackson, J. R. (2003). Premedical Education: The Contribution of Small Local Colleges. J. Rural Health 19, 181-189. doi:10.1111/j.1748-0361.2003.tb00560.x

Conflict of Interest: The authors declare that the research was conducted in the absence of any commercial or financial relationships that could be construed as a potential conflict of interest.

Publisher's Note: All claims expressed in this article are solely those of the authors and do not necessarily represent those of their affiliated organizations, or those of the publisher, the editors and the reviewers. Any product that may be evaluated in this article, or claim that may be made by its manufacturer, is not guaranteed or endorsed by the publisher.

Copyright $\odot 2021$ Guzmán, Barragán and Cala Vitery. This is an open-access article distributed under the terms of the Creative Commons Attribution License (CC BY). The use, distribution or reproduction in other forums is permitted, provided the original author(s) and the copyright owner(s) are credited and that the original publication in this journal is cited, in accordance with accepted academic practice. No use, distribution or reproduction is permitted which does not comply with these terms. 